\title{
DO BUSINESS STUDENTS USE TECHNOLOGY TO CHEAT AND DO BUSINESS FACULTY TAKE ANY ACTIONS ABOUT IT?
}

\author{
Lisa Z. Bain, Rhode Island College, lbain@ric.edu \\ Neelima Bhatnagar,University of Pittsburgh-Johnstown,bhatnagr@pitt.edu
}

\begin{abstract}
Business students use technology to cheat inside and outside of the classroom during traditional, face-to-face college courses. There are many actions business faculty can take to educate students about academic integrity, to prevent cheating, and to report violations when they happen. This research study conducted two surveys, one to business students and a second one to business faculty. The student survey asked students to identify ways that they use technology to cheat. The faculty survey asked faculty to identify the type of actions they take about cheating. The results of the student survey showed that cheating is not rampant. However, it is still happening by many students who in some cases are cheating multiple times during the academic year. The results of the faculty survey showed that faculty are taking many actions but could be doing more to educate students and prevent cheating.
\end{abstract}

Keywords: E-Cheating, Academic Integrity, Academic Dishonesty, Plagiarism, Cheating

\section{INTRODUCTION}

Most faculty members experience some type of student cheating in their courses on a regular basis but rarely does this lead to serious consequences, let alone, student expulsion from the institution. Usually, minor infractions are typical and result in a warning or a zero for an assignment. This will address most first time offences. It just becomes part of the job and hopefully handled with the respect and professionalism it deserves. The more serious cases happen much less frequently and are not a common occurrence each and every semester. Unfortunately, the impact is more severe when a faculty member has to deal with blatant and repetitive academic integrity violations by a single student, as was the case by one of the faculty members prior to this research project. It was a very difficult situation that occurred over three consecutive semesters and in three different courses by the same student. It began as a simple Google search during an exam, proceeded to submission of work copied from an instructor's manual, then on to the use of cell phone during two exams. All of this cheating was fueled by the use of technology and none of it was obvious at the time even with attentive monitoring. All but the first incident was reported to the Vice President of Academic Affairs (VPAA), as required by the institution. In hindsight, the first incident should have been reported as well since appropriate, but maybe not as severe as they should have been, consequences were taken by the instructor. This required two separate hearings that included audio taped testimony by both the instructor and the student. The final violation during a final exam resulted in expulsion of the student from the institution by the VPAA. Even with intense proctoring, the student was able to go undetected in the use of a cell phone except by another student who reported it to the instructor.

Faculty members do not enjoy catching students cheating. It is an uncomfortable situation for all involved and just creates more work for the instructor. In addition, having solid proof of the cheating can be difficult. This can make faculty members hesitant to take any actions, especially reporting it to the appropriate parties. Serious incidents like the one just described leave a lasting and hurtful mark on an instructor. In order to deal with this, it was important for something positive to come out of such a negative experience. The purpose of this research project is to continue to build upon a previous project and hopefully help both students and faculty with academic integrity issues.

This research project is part two of a project that focuses on academic integrity issues for both students and faculty. The first part of the project identified and summarized the ways students use technology to cheat, including using technology inside and outside of the classroom. It also researched the actions that faculty can take in the areas of educating students, preventing incidents, and reporting issues if they happen. In most cases, these actions require little, if any, technological skills by the faculty member. The second part of this project is to follow-up on the first part by conducting two surveys, one to students and a second one to faculty. Both of which focus specifically on 
business students and business faculty since the researchers work in this environment and have direct contact with both parties. This focus also allows the researchers to know if cheating is happening is "our house" since many other surveys are not specific. It also allows the researchers to further investigate the types of cheating by business majors. The student survey asked questions directly related to the types of cheating students supposedly do that use technology and that were identified in the first part of the project. The faculty survey asked questions about whether the faculty member performed the type of actions identified in the first part of the project. The purpose of the two surveys is to ultimately reduce cheating in the classroom and increase the academic integrity of business students. The results of the student survey will be used to educate faculty about the types of cheating students admit to actually doing within the last year. The results of the faculty survey will also be used to help instructors implement techniques that could be helpful in reducing cheating in their classrooms. The next section provides an abbreviated literature review primarily from the first part of the project that includes the most common ways student use technology to cheat and the recommended actions for faculty to address this difficult issue.

\section{LITERATURE REVIEW}

\section{Student Cheating Using Technology}

College students enrolled in traditional, face-to-face courses use technology to cheat inside and outside of the classroom. Cheating happens inside the classroom primarily during exams, tests, and quizzes [7]. This is obviously the most common time that cheating would be necessary for students versus during lectures or other in class activities. Students use electronic devices to access unauthorized information, like accessing the Internet or sending/receiving text messages [5]. Students also use smartphones, programmable calculators, and other devices like iPods [6]. Many of these devices have the capability to access email and most electronic documents, including textbooks [12]. McCabe [10] suggests that the use of electronic devices during tests and exams is not high at only $5 \%$ but still a reason for concern. Other researchers support that e-cheating is increasing [7]. More importantly, these actions still go undetected regardless of faculty proctoring. Students are very skilled at using these devices in deceptive ways inside the classroom. They are also using technology to cheat when they are outside of the classroom.

Cheating happens outside of the classroom while completing various assignments. Students copy information from the Internet and other electronic media and use it as their own [10]. Obviously, this is more difficult for faculty to prevent because students are not in the presence of a faculty member. Students can also purchase materials on the Internet or via email like papers, instructor manuals, and test banks [14]. Again, this is difficult to detect since faculty do not directly see the work being done by the student or are even aware that these items are available to students. Most faculty members are aware of social media but maybe not that it can be used for cheating as well. It is just another convenient way that technology allows students to share information, like exam questions, that promotes cheating [4]. These are many of the most common ways students cheat outside of the classroom. There may be other ways as well that faculty have not yet identified.

The more troubling aspect may be the mentality of the students about their actions. They may not see it as cheating since they are so accustomed to using information from the Web [6]. Does this mean that students do not know what constitutes cheating? Of course they should know. But do they? How would students answer questions directly related to cheating? More specifically, how would business students answer these questions? Having meaningful information about how business students use technology to cheat would help educate business faculty and provide valuable guidance in their course design and policies.

\section{Actions for Faculty}

Regardless of why students cheat, it is important for faculty to understand what is happening in their classrooms and be able to take the appropriate actions. Studies show that certain faculty actions can reduce cheating. These actions include educating the student about academic integrity, using pedagogical techniques to prevent cheating, and reporting incidents of cheating when it does happen. There are many ways to educate students about academic integrity and faculty can certainly choose what works best for them. This may include a separate academic integrity policy, information on a syllabus, or discussing the topic before each assignment [11,8]. Fortunately, there are 
many ways to educate students about the problems associated with cheating. Faculty can get as creative as they like, including using quizzes and/or videos to highlight key items. However, part of this education should be an explanation of the consequences for students involved in academic dishonesty [9].

The second action faculty can take to reduce cheating in their classes is to use techniques that promote prevention. The most obvious of which is to prohibit all electronic devices in the classroom during exams [5]. This must also be reinforced by direct instruction prior to each exam as well as diligent proctoring. Outside of the classroom is a different story. Two of the most important areas for this are student papers and homework assignments. Antiplagiarism software tools like TurnItIn and SafeAssign can help prevent cheating on papers [12]. Other techniques include requiring students to submit papers in pieces, specifying reference requirements, and providing detailed grading rubrics $[13,10]$. In addition, unique paper topics limit the ability of students to reuse papers. This simply reduces the chances that another paper would be available from another course and therefore posted online. The other important area for incorporating prevention is homework assignments. Just like papers, academic integrity experts recommend creating personal and distinctive assignments that are not part of a standard textbook. Offering more frequent, low-stake assignments that include very specific and detailed instruction can also reduce the need for cheating by students $[8,3]$.

The third action faculty can take is to report cheating incidences when they do happen and impose the appropriate consequences. Unfortunately, students know that much of this goes unnoticed and does not get reported [1]. Puccio [13] recommends that faculty should be involved and all offenses should be reported in some way. This can help deter future incidents.

If a faculty member knew that his/her business students were using technology for cheating, would it have an impact? Would it change any of the faculty's actions? Do faculty educate their students about cheating? Do faculty take actions to prevent cheating? Do faculty report cheating when it does happen? This would provide a foundation for justifying certain actions for such faculty and ideally reduce cheating.

The primary goal of the study is to ultimately help business faculty prevent cheating in their classrooms. This was done by conducting two surveys, one for students and one for faculty. The student survey asked business students to identify ways they use technology in completing their course work that may or may not violate academic integrity. The faculty survey asked business faculty to identify actions they may or may not take in educating, preventing, or reporting academic integrity. The methodology section describes the process for conducting the surveys and the results section includes the results from both surveys.

\section{RESEARCH METHODOLOGY}

This research project conducted online surveys to both business students and business faculty at two different institutions. This included a 4-year, medium-sized public college in southern New England and a 4-year, large-sized public university in Pennsylvania. An email with the link to the online surveys was sent to the official school email address of the students and the faculty. Each email included a deadline for completing the survey and stated that the survey was voluntary, confidential, and anonymous. Qualtrics was required by one of the institutions and therefore was used to create and administer the surveys. Both institutions provided approval for conducting each survey by the appropriate business school official and received IRB approval. In addition, one institution required approval of the Office of Institutional Research and Planning for the student survey to ensure another student survey was not being conducted at the same time. The online surveys included a consent screen before any questions displayed. This screen included two options; Yes, I agree to be in the study or Exit and do not complete survey. The "Yes" option proceeded directly to the survey and the "Exit" option did not.

\section{Description of Student Surveys}

The student surveys included questions about common types of e-cheating and basic demographic items. The echeating questions were based off a summary list developed in a previous research study [2]. These included questions about actions students take both inside and outside of the classroom. For the "inside" questions, these included the use of electronic device to access unauthorized information from the Internet, e-mail, e-texts, or 
electronic documents/files and the use of text messaging, programmable calculator, cameras, MP3 players, or wireless earphones/microphones. For the "outside questions, these included copying information from the Internet or electronic media, purchasing papers/documents, instructor manuals, or test banks, using cheating web sites, Amazon's Search Inside the Book, or social media. The demographic questions asked for age, major, level, and gender.

\section{Description of Faculty Surveys}

The faculty surveys included questions about their actions in terms of educating students about academic integrity, preventing incidents, and reporting violations when they do happen. Again, the questions were based off a summary list developed in a previous research study [2]. The "educating" questions asked about maintaining an academic integrity policy, describing plagiarism and academic dishonesty, setting expectations, and explaining academic dishonesty consequences. The "preventing" questions asked about prohibiting use of electronic devices, using antiplagiarism software tools, creating unique assignments, dividing papers into components, applying requirements to sources, assigning low-stake assignments and providing instructions on assignments. The "reporting" questions asked about responding to incidents and penalizing students. The demographic questions asked about gender, title/rank, tenure status, discipline, years teaching, and job status in terms of full-time, part-time, or adjunct.

\section{Student Participants}

The student participants included all current students actively enrolled in a course during the Spring 2015 semester and listed as a business major. The business majors included Accounting, CIS, Economics, Finance, Health Care Administration, Management, or Marketing. This included 1347 students at one institution and 229 at the other for a total of 1576 students.

\section{Faculty Participants}

The faculty participants included all current business faculty and adjuncts actively teaching during the Spring 2015 semester. This included 37 at one institution and 122 at the other for a total of 159 faculty members.

\section{RESULTS}

\section{Student Surveys - Demographics}

The results of the student survey for the demographic, shown in Table 1, are a typical breakdown on the student body at the respective institutions with the exception of level. More females (64\%) completed the survey than males (36\%), which was expected due to the higher enrollment of females in one of the business schools. Almost half $(47 \%)$ of the students that completed the survey were seniors, more than any of the other levels. This could be attributed to the fact that seniors have a higher maturity level in terms of reading their student emails and comfort level of responding to surveys. The mix of majors also reflected similar percentages to the current listing of students, with both accounting major (22\%) and management majors (28\%) with the highest percentages. Although 137 students completed the survey, the response rate was only $9 \%$. This was most likely due to the timing of the survey discussed in the conclusion section.

Table 1. Demographics

\begin{tabular}{|l|c|c|l|l|r|r|}
\hline \multicolumn{1}{|c|}{ Item } & Responses & Percentage & & \multicolumn{1}{c|}{ Item } & Responses & Percentage \\
\hline Gender & & & & Major & & \\
\hline Female & 84 & $64 \%$ & & Accounting & 29 & $22 \%$ \\
\hline Male & 47 & $36 \%$ & & CIS/IS & 9 & $7 \%$ \\
\hline & & & & Economics & 4 & $3 \%$ \\
\hline Level & & & & Finance & 11 & $8 \%$ \\
\hline Freshman & 13 & $10 \%$ & & HCA & 17 & $13 \%$ \\
\hline Sophomore & 21 & $16 \%$ & & Management & 37 & $28 \%$ \\
\hline
\end{tabular}




\begin{tabular}{|l|l|l|l|l|r|r|}
\hline Junior & 35 & $27 \%$ & & Marketing & 18 & $14 \%$ \\
\hline Senior & 62 & $47 \%$ & & Other & 6 & $5 \%$ \\
\hline
\end{tabular}

\section{Student Surveys - Results Inside of the Classroom}

The results of the student surveys for the academic integrity issues that occur inside the classroom, shown in Table 2 , include both encouraging and discouraging information about student activities. On the positive side, a very small percentage of business students use email (4\%), wireless earphones $(2 \%)$ or MP3 players $(1 \%)$ to cheat on exams/tests/quizzes inside the classroom. However, there are many students that do use programmable calculators (12\%), electronic documents/files (9\%), text messages (7\%), and cameras $(6 \%)$ to do so. The area of most concern comes from the use of the Internet (23\%). This type of cheating showed the highest amount of students indicating that they have done this more than two times in the last year with several admitting to doing this five or more times. This may show that if they do not get caught or there are no penalties that they are willing to do it again. Overall, the numbers are relatively low but unfortunately students are still cheating inside the classroom and mostly by using the Internet.

Table 2. Student Survey Results - Inside of the Classroom

\begin{tabular}{|c|c|c|c|c|c|c|c|c|}
\hline \multirow[b]{2}{*}{ The Internet } & \multicolumn{2}{|c|}{ Never } & \multicolumn{2}{|c|}{ 1-2 times } & \multicolumn{2}{|c|}{ 3-4 times } & \multicolumn{2}{|c|}{$\begin{array}{c}5 \text { or more } \\
\text { times }\end{array}$} \\
\hline & 105 & $77 \%$ & & $17 \%$ & 6 & $4 \%$ & 3 & $2 \%$ \\
\hline Email & 131 & $96 \%$ & 4 & $3 \%$ & 0 & $0 \%$ & 2 & $1 \%$ \\
\hline Electronic document/file & 122 & $90 \%$ & 10 & $7 \%$ & 2 & $1 \%$ & 2 & $1 \%$ \\
\hline Text Message & 126 & $93 \%$ & 4 & $3 \%$ & 1 & $1 \%$ & 4 & $3 \%$ \\
\hline Programmable Calculator & 118 & $87 \%$ & 14 & $10 \%$ & 2 & $1 \%$ & 2 & $1 \%$ \\
\hline Camera & 129 & $95 \%$ & 5 & $4 \%$ & 1 & $1 \%$ & 1 & $1 \%$ \\
\hline MP3 Player & 135 & $99 \%$ & 2 & $1 \%$ & 0 & $0 \%$ & 0 & $0 \%$ \\
\hline Wireless Earphones & 134 & $98 \%$ & 2 & $1 \%$ & 1 & $1 \%$ & 0 & $0 \%$ \\
\hline
\end{tabular}

\section{Student Surveys - Results Outside of the Classroom}

For the questions that asked about academic integrity violations outside of the classroom, shown in Table 3, the answers indicate that there are several areas where students are cheating many times using several different methods. The most common relate to the use of social media $(20 \%)$, cheating web sites $(15 \%)$ and copying information from the Internet (12\%). Social media is not surprising since most students use this type of technology on a daily basis. Use of cheating web sites seems more blatant and an area of concern more so than social media. In some cases, students do not realize that use of social media is cheating. Students should know but many still need education about using social media for course work. In the case of cheating web sites, the use of these is a very obvious violation of academic integrity. Cheating web sites are very similar to purchasing solution/instructor manuals (8\%) in terms of students knowing that using them is wrong. Although the number of students that admitted to purchases these was low at 11 that is still too many. The same is true for copying information from electronic media (8\%). The numbers are low but this is still cheating. Fortunately, not very many students had used Amazon's Search Inside the Book (4\%), purchased papers/documents $(1 \%)$, or purchased test banks $(1 \%)$. It appears that using items that require some type of payment are used less than items that are free to students. Again, overall the number of students cheating outside of the classroom is relatively small but many are still using technology in many ways that violate academic integrity. 
Table 3. Student Survey Results - Outside of the Classroom

\begin{tabular}{|c|c|c|c|c|c|c|c|c|}
\hline & \multicolumn{2}{|c|}{ Never } & \multicolumn{2}{|c|}{ 1-2 times } & \multicolumn{2}{|c|}{ 3-4 times } & \multicolumn{2}{|c|}{$\begin{array}{c}5 \text { or more } \\
\text { times }\end{array}$} \\
\hline Copied info from the Internet & 117 & $88 \%$ & & $10 \%$ & 3 & $2 \%$ & 0 & $0 \%$ \\
\hline Copied info from the electronic media & 122 & $92 \%$ & 11 & $8 \%$ & 0 & $0 \%$ & 0 & $0 \%$ \\
\hline Purchased papers/documents & 132 & $99 \%$ & 0 & $0 \%$ & 0 & $0 \%$ & 1 & $1 \%$ \\
\hline Purchased solution/instructor manuals & 122 & $92 \%$ & 11 & $8 \%$ & 0 & $0 \%$ & 0 & $0 \%$ \\
\hline Purchased test banks & 132 & $99 \%$ & 1 & $1 \%$ & 0 & $0 \%$ & 0 & $0 \%$ \\
\hline Used cheating web sites & 113 & $85 \%$ & 15 & $11 \%$ & 3 & $2 \%$ & 2 & $2 \%$ \\
\hline Used Amazon's Search Inside the Book & 128 & $97 \%$ & 4 & $3 \%$ & 0 & $0 \%$ & 0 & $0 \%$ \\
\hline Used social media & 106 & $80 \%$ & 20 & $15 \%$ & 4 & $3 \%$ & 3 & $2 \%$ \\
\hline
\end{tabular}

\section{Faculty Survey Results- Demographics}

The results of the faculty surveys demographics, shown in Table 4, indicate a relatively even mix of genders, titles, and tenure/non-tenured. There were only 28 responses from faculty but the gender breakdown included about half female $(57 \%)$ and male $(43 \%)$. As for the title/rank of the respondents, there was a welcomed distribution primarily among the three main ranks of Assistant Professor (32\%), Associate Professor (11\%), and Full Professor (7\%) as well as the tenure (46\%) and non-tenured (46\%). The majority of the faculty came from the Accounting (36\%) and the Management (32\%) disciplines with all the other disciplines represented with the exception of Finance. The majority of the faculty that answered the survey indicated that their job status was full time (96\%). Overall, the response rate was low at $18 \%$ but much higher than the student survey and again most likely due to the timing of the survey.

Table 4. Faculty Survey - Demographics

\begin{tabular}{|l|c|r|l|l|r|r|l|l|c|r|}
\hline Item & $\#$ & Per & & Item & $\#$ & Per & & Item & $\#$ & Per \\
\hline Gender & & & & Discipline & & & & Tenure & & \\
\hline Female & 16 & $57 \%$ & & Accounting & 10 & $36 \%$ & & Tenured & 13 & $46 \%$ \\
\hline Male & 12 & $43 \%$ & & CIS & 1 & $4 \%$ & & Tenure Tr & 2 & $7 \%$ \\
\hline & & & & Economics & 4 & $14 \%$ & & NonTenure & 13 & $46 \%$ \\
\hline Title/Rank & & & & Finance & 0 & $4 \%$ & & & & \\
\hline Adjunct & 1 & $4 \%$ & & HCA & 1 & $0 \%$ & & Job Status & & \\
\hline Assistant & 9 & $32 \%$ & & Management & 9 & $32 \%$ & & Full Time & 27 & $96 \%$ \\
\hline Associate & 11 & $39 \%$ & & Marketing & 2 & $7 \%$ & & Part Time & 0 & $0 \%$ \\
\hline Full & 7 & $25 \%$ & & & & & & Adjunct & 1 & $4 \%$ \\
\hline & & & & & & & & & & \\
\hline
\end{tabular}

\section{Faculty Survey Results - Educating Students about Academic Integrity}

The results of the faculty surveys for the questions related to educating students about academic integrity, shown in Table 5 and Table 6, demonstrate that faculty are taking some actions to educate students but could take additional actions. Most faculty (97\%) include an academic integrity policy on their syllabi, discuss dishonesty in their classes $(90 \%)$, and explain the consequences $(83 \%)$. However, the percentages are much lower for discussing academic integrity for each writing assignment (53\%), each exam/test/quiz (37\%) and each assignment (23\%). As a faculty member, it is understandable why this is lower because of the time required to do this for each assignment. These last three items are areas that could improve the understanding and education of students about academic integrity and help reduce cheating in courses.

Table 5. Faculty Survey Results - Educating

Do you include/discuss academic integrity information:

\begin{tabular}{|l|lr|rrr|c|}
\hline & \multicolumn{2}{|c|}{ Yes } & \multicolumn{2}{|c|}{ No } & NA \\
\hline For each assignment? & \multicolumn{2}{|c|}{$7 \quad 23 \%$} & 23 & $77 \%$ & 0 & $0 \%$ \\
\hline
\end{tabular}


Issues in Information Systems

Volume 16, Issue III, pp. 199-208, 2015

\begin{tabular}{|c|c|c|c|}
\hline For each exam/test/quiz? & $11 \quad 37 \%$ & $18 \quad 60 \%$ & $13 \%$ \\
\hline For each writing assignment? & $53 \%$ & $1240 \%$ & $27 \%$ \\
\hline Do you include an academic integrity policy on your syllabus? & $97 \%$ & $13 \%$ & $0 \%$ \\
\hline
\end{tabular}

Table 6. Faculty Survey Results - Educating

\begin{tabular}{|l|r|r|rr|rr|r|}
\hline How often per semester do you: \\
\hline
\end{tabular}

\section{Faculty Survey Results - Preventing Academic Integrity Issues}

The results of the faculty surveys for the questions related to preventing academic integrity issues, shown in Tables 7-9, again indicate that faculty are taking some actions to prevent cheating but could take additional actions. Most faculty $(82 \%)$ prohibit the use of electronic devices during in class exams/tests/quizzes and use low-stake assignments $(80 \%)$. This is very encouraging and almost expected of faculty. However, $23 \%$ of students claim they are still using their electronic devices to access the Internet during exams/tests/quizzes based on the student surveys. There is a slight disconnect here. Faculty may not see this happening or are not thoroughly proctoring. Students are very skilled at doing this without being seen. As for using rubrics, half or more of faculty use them for assignments $(54 \%)$ and papers $(50 \%)$. A little over half of the faculty members create their own assignments (54\%). Just a few less are using anti-plagiarism software (46)\%. These last few items are areas for improvement.

The last area of prevention focused on student papers. Here, a large number of the faculty that responded have students submit a whole paper (63\%) versus submitting one component at a time and allow students to choice their own references $(61 \%)$. This can encourage cheating by allowing students to purchase papers or reuse papers from other sources. Although only one student reported in the student survey that he/she had purchased a paper from an online source, it was done five or more times. Overall, the actions taken by faculty contribute to preventing cheating but more faculty could implement many of these prevention techniques into their courses.

Table 7. Faculty Survey Results - Preventing

\begin{tabular}{|l|rr|rrr|r|}
\hline & \multicolumn{2}{|c|}{ Yes } & \multicolumn{2}{|c|}{ No } & \multicolumn{2}{|c|}{ NA } \\
\hline $\begin{array}{l}\text { Do you prohibit use of electronic devices during in class } \\
\text { exams/tests/quizzes? }\end{array}$ & 23 & $82 \%$ & 4 & $14 \%$ & 1 & $14 \%$ \\
\hline Do you use anti-plagiarism software for student papers? & 12 & $46 \%$ & 13 & $46 \%$ & 3 & $11 \%$ \\
\hline Do you use rubrics for student assignments? & 14 & $54 \%$ & 12 & $46 \%$ & 0 & $0 \%$ \\
\hline Do you use rubrics for student papers? & 14 & $50 \%$ & 11 & $39 \%$ & 3 & $11 \%$ \\
\hline
\end{tabular}

Table 8. Faculty Survey Results - Preventing

\begin{tabular}{|c|c|c|c|c|}
\hline & Never & 1-2 times & 3-4 times & $\begin{array}{c}5 \text { or more } \\
\text { times }\end{array}$ \\
\hline $\begin{array}{l}\text { How often per semester do you assign } \\
\text { low-stake assignments? }\end{array}$ & $5 \quad 20 \%$ & $6 \quad 24 \%$ & $4 \quad 16 \%$ & $\begin{array}{ll}6 & 24 \%\end{array}$ \\
\hline
\end{tabular}

Table 9. Faculty Survey Results - Preventing

\begin{tabular}{|c|c|c|c|c|}
\hline & Create my own & $\begin{array}{c}\text { Use } \\
\text { assignments in } \\
\text { the textbook }\end{array}$ & $\begin{array}{c}\text { Use } \\
\text { assignments } \\
\text { from other } \\
\text { textbooks }\end{array}$ & Other \\
\hline $\begin{array}{l}\text { How do you select or create } \\
\text { assignments for your courses? }\end{array}$ & $15 \quad 54 \%$ & $5 \quad 18 \%$ & $14 \%$ & $7 \quad 25 \%$ \\
\hline
\end{tabular}


Issues in Information Systems

Volume 16, Issue III, pp. 199-208, 2015

Table 10. Faculty Survey Results - Preventing

\begin{tabular}{|c|c|c|c|c|}
\hline & Components & Whole Paper & Other & NA \\
\hline $\begin{array}{l}\text { What method do you use for } \\
\text { submission of papers? }\end{array}$ & $27 \%$ & $17 \quad 63 \%$ & $5 \quad 19 \%$ & $11 \%$ \\
\hline
\end{tabular}

Table 11. Faculty Survey Results - Preventing

\begin{tabular}{|c|c|c|c|c|}
\hline & Student choice & Required & Other & NA \\
\hline $\begin{array}{l}\text { What method do you use for references } \\
\text { for papers? }\end{array}$ & $17 \quad 61 \%$ & $3 \quad 11 \%$ & $311 \%$ & $5 \quad 18 \%$ \\
\hline
\end{tabular}

\section{Faculty Survey Results - Reporting Academic Integrity Issues}

The results of the faculty surveys for the questions related to reporting academic integrity issues, shown in Table 12 , are very encouraging and demonstrate that the majority of faculty members are responding to student cheating. Most faculty members (75\%) respond to an incident of academic dishonesty and about the same (71\%) penalize students with appropriate consequences. According to academic integrity experts, all incidents should be addressed with the appropriate consequences [13]. There were several respondents that indicated they do not always respond or penalize students. This is a concern that should be addressed. In some cases, it is very difficult to take either of these actions due to the lack of proof or fear of retribution by the student or administration. Faculty can be placed in challenging situations where there is lack of substantial proof. In the case of this survey, it was encouraging that most faculty members are responding to academic integrity violations.

Table 12. Faculty Survey Results - Reporting

\begin{tabular}{|c|c|c|c|c|}
\hline & Always & Sometimes & Seldom & Never \\
\hline $\begin{array}{l}\text { How often do you respond to an } \\
\text { incident of academic dishonesty? }\end{array}$ & $21 \quad 75 \%$ & $27 \%$ & $27 \%$ & $14 \%$ \\
\hline $\begin{array}{l}\text { How often do you penalize students for } \\
\text { academic dishonesty with appropriate } \\
\text { consequences? }\end{array}$ & $20 \quad 71 \%$ & $311 \%$ & $7 \%$ & $0 \quad 0 \%$ \\
\hline
\end{tabular}

\section{CONCLUSIONS}

\section{Student Surveys}

Business students are currently using technology to cheat inside and outside of the classroom. Fortunately this does not appear to be rampant or done by the majority of students. However, it is still happening and by many students who in some cases are cheating multiple times. Inside the classroom is where students tend to use the electronic devices to cheat on exams/tests/quizzes by accessing information mostly from the Internet. They are also accessing emails, files, and text messages while in the classroom as well as using cameras and calculators. The majority of faculty members ban electronic devices but this is still occurring and in many cases students are doing this multiple times per academic year. Cheating is not limited to inside the classroom, it happens outside of class as well.

Outside of the classroom provides more options and opportunities to cheat and students are still taking advantage of technology to violate academic integrity. This mainly includes using social media, cheating web sites, and copying information from the Internet. Technology allows each of these to exist and provides a free, easy, and convenient way to access unauthorized information for a variety of course work. Faculty members need to be aware that students not only have access to this but also that they are using it on a regular basis. Less often, students are buying papers, instructor manuals, and test banks from online sources. The good news is that the number of students buying these items is much less then the students cheating in other ways.

Although 137 students completed the survey, the response rate was only $9 \%$. This could be a result of the timing of the survey or the topic of the survey. The survey was conducted in the last week of the semester during final exams at one institution and two weeks after the end of the semester at the other institution. This was not done by design 
but due to a delay in IRB approval. Ideally, the survey should have been sent several weeks earlier to allow students to respond during a non-peak time or at least while the semester was in session. This was the first time this type of survey was conducted at each institution and the researchers are considering conducting the survey again at the beginning of a semester in the future to improve the response rate. Also, the topic of survey could be considered sensitive to many students preventing completion. The consent screen for the survey indicated that the survey was confidential and anonymous. However, students still may not have felt comfortable admitting to cheating or may not have given accurate or truthful answers. This is a known limitation of conducting surveys of this type. In addition, the researchers felt concern that the questions on the survey may give students ideas of ways to cheat. This, of course, would defeat the purpose of reducing academic integrity issues. Regardless, the main purpose of the student survey was to identify if cheating was happening on our campuses in order to educate faculty. Any type of information sessions, like a brown bag, will include a discussion of the limitations of the surveys.

Another limitation of the survey is the mindset of students about cheating. Students may or may not realize or believe many of their actions are cheating due to a variety of reasons. This was not the focus of the research study but should be considered especially since cheating/lying or misrepresentation happens in the business environment, including but not limited to Information Technology professionals. However, the survey results are not necessarily generalizable to the wider population of business professionals.

\section{Faculty Surveys}

Business faculty members are taking actions about academic integrity violations by business students but could be doing more. As for educating students, faculty members are diligent about discussing academic integrity in general in their syllabi and in their classes. This includes educating students about the penalties and possible consequences. However, they could do more for individual items of course work like assignments, exams, and papers. Students may respond better if the topic is addressed more frequently during the semester and across different items. This would reinforce the importance of academic integrity on a regular basis and increase student knowledge and awareness.

In a similar fashion, faculty members are taking some very important and recommended actions to prevent cheating, like banning electronic devices during exams, but could take additional actions for the submission of papers. Although faculty members are banning these devices, students are still using them somehow. Personal experience proves that students are extremely savvy in hiding the use of smartphones during exams. A new type of proctoring may be necessary to prevent this from happening. One faculty member mentioned her policy of making students place their smartphones directly on the desk/table in plain sight. This sound like a reasonable solution until she stated that a student brought a second hidden smartphone from which to cheat. The bottom line is that faculty members need to be aware that this is happening and take appropriate actions in their classrooms. In addition, faculty members could use more rubrics and techniques for papers, like anti-plagiarism tools, component submissions, and required resources/references. In most cases, these techniques require little if any computer skills and training, with the exception of the anti-plagiarism tools. They do, however, necessitate modifications in course design.

Lastly, it was encouraging that most faculty members are responding to academic integrity violations by reporting incidents and penalizing students. Students not only deserve this response but other students need to see and hear about faculty taking such actions. Knowing that there are legitimate consequences can seriously impact whether a students decides to cheat in the first place.

\section{Academic Integrity}

The main purpose of this research project was to hopefully prevent another faculty member from having to go through the process of being involved in a student getting expelled from an institution for cheating. The first part of the project identified ways that students cheat using technology and the actions that faculty can take to educate students, prevent cheating, and report it when it does happen. The second part of the project surveyed students and faculty using the items indentified in the first part. The results of both surveys provided a wide range of interesting information. Knowing that business students are using technology to cheat inside and outside of classroom provides 
validation that can be presented to current business faculty members as proof that it is happening in their classrooms.

The faculty survey showed which actions are being used and which ones are not. Both survey results can then be used to help educate faculty on how to improve their course design and reduce the chances of being in a situation where they have to testify about academic integrity violations.

\section{REFERENCES}

1. AIM (2014). Academic Integrity Matters Petition. Accessed May 29, 2014. Retrieved from http://ucsdaim.org/petition/.

2. Bain, L.Z. (2014). How Students Use Technology to Cheat and What Faculty Can Do About It. Information Systems Education Journal (ISEDJ), (13) 5, 92-99.

3. Baldwin, A, (May 2001) Practice Plagiarism Prevention, The Teaching Professor, 15 (5).

4. Bi, F. (2013). Better Data Can Help Colleges Fight Cheating. Chronicle of Higher Education. September 9, 2013. Accessed May 29, 2014. Retrieved from http://chronicle.com/article/Better-Data-Can-HelpColleges/141485

5. Jones, K. O., Reid, J., \& Bartlett, R. (2008). "Cyber Cheating in an Information Technology Age". "Acdemic Cyberplagiarism" [online dossier]. Digithum. No. 10. UOC. [Accessed: 5/9/2014]. Retrieved from http://www.uoc.edu/digithum/10/dt/eng/jones_reid_bartlett.pdf

6. Khan, Z. R. \& Balasubramanian, S. (2012). Students go click, flick and cheat: E-cheating, technologies and more. Journal of Academic and Business Ethics, (6), 1-25.

7. King, D. L. \& Case, C. J. (2014). E-cheating: Incidence and Trends Among College Students. Issues in Information Systems, (15) I, 20-27.

8. Lang, J. M. (2013). Cheating Lessons, Part 2. The Chronicle of Higher Education. Accessed May 29, 2014. Retrieved from http://chronicle.com/article/Cheating-Lessons-Part-2/140113

9. McCabe, D. L. \& Pavela, G. (2004). Ten [Updated] Principles of Academic Integrity. Change. May/June 36(3).

10. McCabe, D. L. (2005). Cheating among college and university students: A North American perspective. International Journal for Educational Integrity, 1(1), 1-11.

11. Novotney, A. (2011). Beat the cheat. Monitor on Psychology, 42(6). Retrieved from http://www.apa.org/monitor/2011/06/cheat.aspx.

12. O’Neil (2003). Technology and Academic Integrity, Cheating Goes Cyber. Information Systems Education Journal, 1(3).

13. Puccio, P. (2008). Encouraging Academic Honesty through Active Plagiarism Instruction and Prevention. Essays from E-xcellence in Teaching (Vol 7). Retrieved from the Society for the Teaching of Psychology Web site: http://teachpsych.org/resources/e-books/eit2007/eit2007.php.

14. Sterngold, A. (2012). Confronting Plagiarism: How Conventional Teaching Invites Cyber-Cheating. Change, $36(3), 16-21$. 